Research Article

\title{
Effect of Naringin Treatment on Postmenopausal Osteoporosis in Ovariectomized Rats: A Meta-Analysis and Systematic Review
}

\author{
Zhu Zhu $\mathbb{D}^{1,2}$ Wenjing Xie $\mathbb{D}^{1},{ }^{2}$ Yanyan Li $\mathbb{D}^{2},{ }^{2}$ Zaiou Zhu $\mathbb{D}^{1,3}$ and Wei Zhang ${ }^{1}{ }^{1}$ \\ ${ }^{1}$ Jiangsu Key Laboratory of Oral Diseases, Nanjing Medical University, Nanjing, Jiangsu, China \\ ${ }^{2}$ Department of Oral Special Consultation, Affiliated Stomatological Hospital of Nanjing Medical University, \\ Nanjing, Jiangsu, China \\ ${ }^{3}$ Department of Oral and Maxillofacial Surgery, Affiliated Stomatological Hospital of Nanjing Medical University, Nanjing, \\ Jiangsu, China
}

Correspondence should be addressed to Wei Zhang; sxm813121@163.com

Received 5 August 2020; Revised 30 September 2020; Accepted 28 January 2021; Published 10 February 2021

Academic Editor: Arham Shabbir

Copyright $(2021$ Zhu Zhu et al. This is an open access article distributed under the Creative Commons Attribution License, which permits unrestricted use, distribution, and reproduction in any medium, provided the original work is properly cited.

Background. Osteoporosis is a major disease that affects the quality of life of middle-aged and old people, so it is very important to find efficient and safe drugs to treat osteoporosis. The purpose of this study was to investigate the therapeutic effect of naringin on postmenopausal osteoporosis in ovariectomized (OVX) rats. Methods. Chinese biomedical databases, CNKI, PubMed, EMBASE, and Wan Fang were searched for articles from inception to March 2020. Two independent researchers screened articles according to inclusion criteria. RevMan 5.3 was used for data analysis. Results. Ten studies were included in the systematic review. The bone mineral density (BMD) significantly increased after naringin treatment (weighted mean difference, 0.06; 95\% CI, 0.03-0.09; $P<0.01$ ). There was no significant increase in BMD after estrogen treatment compared with naringin (weighted mean difference, $0.00 ; 95 \% \mathrm{CI},-0.00$ to $0.01 ; P=0.06)$. The trabecular bone volume (BV/TV) (weighted mean difference, 2.09; 95\% CI, 1.85-2.34; $P<0.01$ ) and trabecular thickness $(\mathrm{Tb} . \mathrm{Th}$ ) (weighted mean difference, 6.65; 95\% CI, 6.55-6.74; $P<0.01$ ) significantly increased after using naringin. Conclusions. Naringin had been shown to promote bone formation in OVX rats. However, the mechanism of naringin needs more research to confirm.

\section{Background}

Osteoporosis is a global public health problem, which primarily threatens postmenopausal women and senior citizens [1]. The pathological characteristics of osteoporosis include bone mineral density (BMD) reduction, bone microstructure deterioration, and matrix protein degradation, resulting in an increased bone fragility and risk of fracture [2]. It not only reduces the quality of life of the elderly, but also causes huge financial burden to patients' families and society. Postmenopausal osteoporosis is the most common type of osteoporosis [3]. At menopause, estrogen withdrawal accelerates bone remodeling with a net increase in bone resorption, which leads to bone loss and even osteoporosis $[4,5]$. The ovariectomized (OVX) rats are the most commonly used animal models to study postmenopausal osteoporosis. In fact, so far, a fully curative treatment for osteoporosis has yet to be developed. In an effort to discover new drugs that treat osteoporosis effectively, much focus has been put on the pursuit of natural-based products because of their availability, cost-effectiveness, and biological activity.

Naringin, a polymethoxylated flavonoid glycoside, is the main bioactive flavonoid extracted from citrus fruits $[6,7]$ and has a positive effect on osteoporosis caused by postmenopause, glucocorticoid, orchidectomy, and aging [8]. Studies have shown that naringin can promote the differentiation and proliferation of various types of cells [9-12] and improve the bone mass in an osteoporotic rat model [9]. Naringin also promotes osteoclast apoptosis through the mitochondrial-mediated apoptotic pathway, so as to inhibit bone loss in OVX rat models and exhibit antiosteoporotic pharmacological activity $[13,14]$. 
The main purpose of this systematic review was to collect and analyze all the data available to investigate the therapeutic effect of naringin on postmenopausal osteoporosis in OVX rats.

\section{Methods}

2.1. Selection of Studies. All articles published in Chinese and English databases from their inception to March 2020 were searched, including Chinese Biomedical databases, CNKI, PubMed, EMBASE, and Wan Fang. Search keywords were as follows: ovariectomized, ovariectomy, ovariectomies, bone diseases, osteoporosis, bone loss, bone mineral density, naringin (And or OR). Meanwhile, the references of selected articles were used as a supplement. There were no language restrictions. This review followed the Preferred Reporting Items for Systematic Reviews and Meta-Analyses (PRISMA) reporting criteria [15]. The Stroke Therapy Academic Industry Roundtable (STAIR) list was used for methodological quality assessment in our study [16].

2.2. Inclusion and Exclusion Criteria. Studies were included if they met all of the following criteria: studies with (1) experimental and control groups; (2) OVX-induced bone loss and osteoporosis; (3) evaluation of therapeutic effects of naringin. Exclusion criteria were as follows: (1) duplicate articles; (2) studies without control groups; (3) studies without the use of BMD; (4) all clinical case reports and only in vitro studies.

2.3. Data Extraction. According to inclusion criteria, two investigators (Z. Z. and W. X.) independently scrutinized all articles and the reference list of all relevant articles was also screened to identify other potential data sources. Data were also extracted from these studies independently by two investigators (Z. Z. and W. X.) using a spreadsheet, including column names of the first author, publication date, the age and species of animal studies, experimental designs, naringin treatment dosage, administration time, and intervention protocols. If two authors disagreed on the choice of research and data interpretation, inconsistencies were settled by discussion with another independent investigator (Y. L.). The final results needed to be discussed with all the investigators to reach a consensus.

2.4. Statistical Analysis. Statistical analyses were performed using RevMan 5.3 (Cochrane Collaboration, Oxford, United Kingdom). Heterogeneity among studies was assessed using the $I^{2}$ statistic [17]. $\mathrm{I}^{2}<50 \%$ meant that the homogeneity of the study was high and there was no significant heterogeneity, so the fixed effect model should be used. Otherwise, the random effect model was used. $P<0.05$ indicated significant differences between groups. Continuous variable data were analyzed with the relative risk or weighted mean difference and its $95 \%$ confidence interval (CI).

\section{Results}

3.1. Selection of Studies. A total of 241 related studies were selected by searching the databases and the literature references of the articles retrieved. After deleting duplicates, 47 studies remained by reading their titles and abstracts. A thorough review of the remaining 47 articles was carried out, of which 37 articles were excluded. The reason for exclusion was the absence of BMD measurements, being clinic reports, or studies only in vitro. Ultimately, 10 studies (three studies were published in Chinese and seven studies were published in English) were selected [8, 9, 18-25] for this systematic review. The flow diagram of the study selection process is shown in Figure 1.

3.2. Characteristics of the Included Studies. Characteristics of the studies are shown in Table 1. Eight studies used SpragueDawley (80\%) female rats, one study [18] used C57/BL6j (10\%) female rats, and another study [21] did not specify which animal model to use. The age range of OVX in rats was $1 \sim 6$ weeks, except for one study which did not report the age of the rats. In a total of 10 studies, the animal sample size ranged from 20 to 75 , and the median sample size was 48 rats. All the studies were administered by oral gavage. The daily dosage range of naringin was $1-1500 \mathrm{mg} / \mathrm{kg}$. The duration of naringin administration varied from 2 to 13 weeks. In all studies, BMD was used to evaluate the results. 3 studies provided data on trabecular bone volume (BV/TV) and trabecular thickness (Tb.Th).

3.3. Risk of Bias. In general, the methodological quality of the studies was not high. None of the studies included any description of sample size calculation or inclusion and exclusion criteria. All studies had reported randomization; however, none of them described allocation concealment. Further, none of the studies reported on their sources of funding or support or any potential conflicts of interest. Table 2 shows the risk of bias reported for each publication included in this meta-analysis.

\subsection{BMD BV/TV Tb.Th Changes after Using Naringin.}

Due to the high heterogeneity of the study, we adopted the random effect model. Compared with the blank control group, the BMD significantly increased after naringin treatment (ten studies, $n=101$; weighted mean difference, 0.06; 95\% CI, 0.03-0.09; $P<0.01$ ) (Figure 2). Besides, in studies where estrogen treatment served as the positive control group, we found that there was no significant increase in BMD after estrogen treatment compared with naringin (three studies, $n=32$; weighted mean difference, 0.00 ; $95 \% \mathrm{CI},-0.00$ to $0.01 ; P=0.06$ ) (Figure 3 ).

Only three studies $[8,21,22]$ used BV/TV, Tb.Th as outcome measures. The BV/TV (\%) values significantly increased after using naringin (three studies, $n=31$; weighted mean difference, 2.09 ; 95\% CI, 1.85-2.34; $P<0.01$ ) (Figure 4). There was a statistically significant difference in Tb.Th (um) values between the two groups. The weighted 


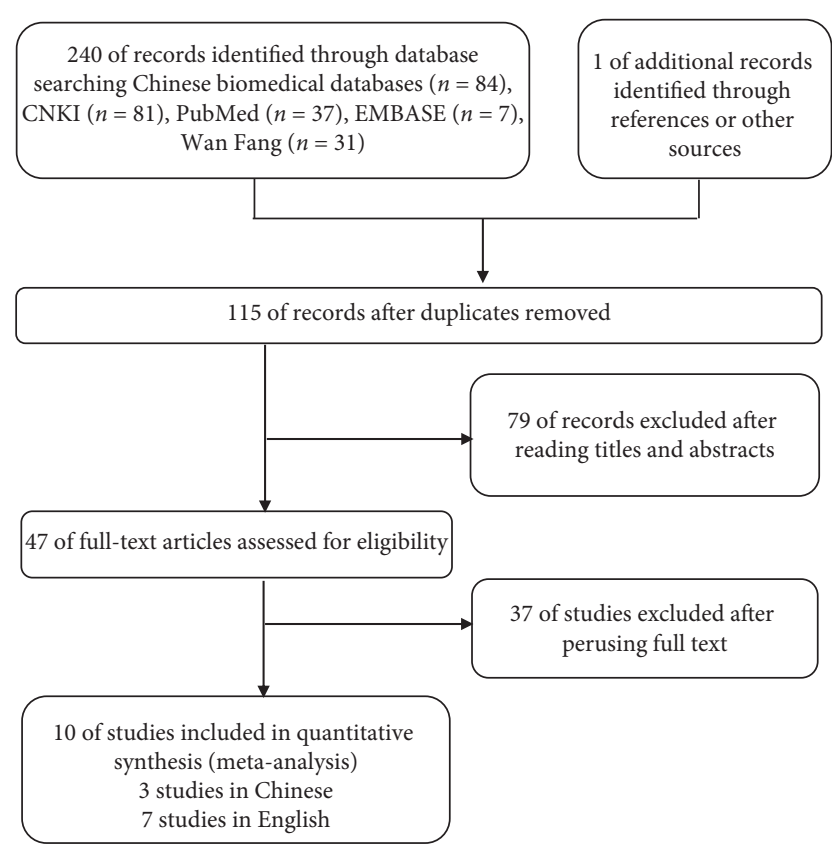

FIGURE 1: Flow diagram of the article selection process for review of Chinese biomedical databases, CNKI, PubMed, EMBASE, and Wan Fang.

mean difference was found to be 6.65, with $95 \%$ $\mathrm{CI}=6.55-6.74$ and $P<0.01$ (Figure 5).

\section{Discussion}

Osteoporosis is an age-related disease that affects millions of people. Although the application of traditional Chinese medicine in the treatment of osteoporosis has a long history, its specific mechanism is not known yet [26]. The research on the monomer of traditional Chinese medicine still remains in basic research. For this, we focus our attention on animal models.

OVX is mainly used to establish animal models of osteoporosis [27]. OVX reduces the level of estrogen and induces bone loss in animals, which is similar to postmenopausal bone loss [28], including rapid bone loss and bone resorption, as well as similar bone reactions to therapy with estrogen, bisphosphonates, tamoxifen, and calcitonin. These wide-ranging similarities make OVX animal models widely used as clinically relevant models of postmenopausal bone loss in women [29]. The OVX rat model was approved by the US Food and Drug Administration (FDA) as a preclinical model [30]. Systematic reviews of animal experiments can improve the accuracy of clinical trial effectiveness prediction, reduce the risk of negative results, and also determine when clinical results of animal experiments can be accepted and terminate unnecessary clinical trials.

As far as we know, this is the first meta-analysis to report the effect of naringin on bone mass in OVX rats. We used random effect models to study. The results showed that the BMD value of the experimental group increased significantly, indicating that naringin could promote bone formation in OVX rats and improve osteoporosis caused by estrogen deficiency. In addition, the effect of naringin in OVX rats was not significantly different from that of estrogen, suggesting that the mechanism of naringin may be the same as that of estrogen, giving us a new direction of research. Compared with the control group, the BV/TV and $\mathrm{Tb}$.Th values of naringin treated group were significantly higher, which also proved the effect of naringin on bone formation.

BMD is an important sign of bone quality, which is of great significance in medicine [31]. It is of great significance in the occurrence, diagnosis, treatment, prognosis, and follow-up observation of osteoporosis, osteomalacia, fibrosis, and other diseases that affect calcium and phosphorus metabolism [32]. BMD was calculated by $\mathrm{x}$-ray absorption of bone. In all ten studies, most of the studies were conducted with dual energy $\mathrm{x}$-ray absorptiometry (DEXA).

With the help of image processing software, regions of interest (ROI) can be selected on the scanning image of micro-CT for threshold segmentation, so that cortical bone and cancellous bone can be segmented and extracted into different tissue regions, respectively [33]. Finally, various morphological characteristics of cortical bone and cancellous bone (trabecular bone) can be studied and analyzed. In general, when the bone tissue in the ROI is the same, the BV/ TV value can reflect the bone mass, which is a common index for evaluating the bone mass of cortical bone and cancellous bone [34]. For the cancellous bone in the medullary cavity, the BV/TV value can reflect the trabecular bone mass of different samples. The increased value indicates that bone metabolism is greater than catabolism and bone mass increases, thereby indirectly reflecting bone metabolism. It has the same value in evaluating bone mass and bone metabolism in the middle part of long bone.

The porous trabecular structure connected with trabecular bone is regularly arranged in accordance with the stress curve and has nonuniform anisotropy. This arrangement can increase the bone strength [35]. It can be said that the bone mass of the bone trabeculae is closely related to its microstructure. Therefore, the microstructural analysis of trabecular bone is very important in bone analysis. MicroCT can perform nondestructive $3 \mathrm{D}$ imaging of trabecular bone microstructure and display the microstructure of trabecular bone, making it possible to analyze the topology of trabecular bone microstructure [36]. Tb.Th is one of the main indexes to evaluate the spatial structure of trabeculae [37]. When bone catabolism is greater than bone anabolism, such as in the case of osteoporosis, the Tb.Th value decreases, whereas it increases when bone anabolism is greater than bone catabolism.

Functions of naringin in bone development are largely unknown. Many studies have reported the potential mechanism of naringin promoting osteogenesis. Wang et al. observed that coadministration of AMPK and Akt inhibitors partly reversed naringin effects in vivo, suggesting that the osteogenic activity of this flavonoid is in part via its stimulation of the Wnt/b-catenin signaling upon interaction with AMPK and Akt [20]. Studies found that naringin inhibits osteoclast formation and bone resorption by the suppression of RANKL-induced activation of NF-kB and 
TABLE 1: Characteristics of the included studies.

\begin{tabular}{|c|c|c|c|c|c|c|}
\hline Study & Animals & Age, mo & $\begin{array}{c}\text { Sample } \\
\text { size }\end{array}$ & Experimental group & Control group & Duration, wk \\
\hline $\begin{array}{l}\text { Pang et al } \\
2010\end{array}$ & $\begin{array}{l}\text { C57/BL6J } \\
\text { mice }\end{array}$ & 1 & $\begin{array}{c}10 / 10 / 10 / \\
10 / 10\end{array}$ & $\begin{array}{c}\mathrm{A}: \text { OVX + naringin }(200 \mathrm{mg} / \mathrm{kg} \\
\text { daily }) ; \mathrm{B}: \mathrm{OVX}+\text { naringin } \\
(400 \mathrm{mg} / \mathrm{kg} \text { daily })\end{array}$ & $\begin{array}{l}\text { A: sham vehicle (2\% ethanol); B: } \\
\text { OVX + vehicle; C:OVX + 17b- } \\
\text { estradiol (E2, } 2 \text { ug/g daily) }\end{array}$ & 6 \\
\hline $\begin{array}{l}\text { Shangguan } \\
\text { et al. } 2017\end{array}$ & $\begin{array}{l}\text { SD rats (body } \\
\text { weight, } \\
220 \pm 8 \mathrm{~g})\end{array}$ & 6 & $\begin{array}{c}12 / 12 / 12 / \\
12\end{array}$ & $\begin{array}{c}\text { A : OVX + naringin }(200 \mathrm{mg} / \mathrm{kg} \\
\text { daily }) ; \mathrm{B}: \mathrm{OVX}+\text { naringin } \\
(100 \mathrm{mg} / \mathrm{kg} \text { daily })\end{array}$ & $\begin{array}{l}\text { A: sham group (physiological } \\
\text { saline solution, } 6 \mathrm{ml} / \mathrm{kg} \text { daily); B : } \\
\text { OVX group (physiological saline } \\
\text { solution, } 6 \mathrm{ml} / \mathrm{kg} \text { daily) }\end{array}$ & 12 \\
\hline Li et al. 2014 & $\begin{array}{l}\text { SD rats (body } \\
\text { weight, } \\
230 \pm 10 \mathrm{~g})\end{array}$ & 6 & $\begin{array}{c}10 / 10 / 10 / \\
10 / 10 / 10\end{array}$ & $\begin{array}{c}\text { A : OVX + naringin }(40 \mathrm{mg} / \mathrm{kg} \\
\text { daily); } \mathrm{B}: \text { OVX + naringin } \\
(100 \mathrm{mg} / \mathrm{kg} \text { daily }) ; \mathrm{C}: \\
\text { OVX + naringin }(200 \mathrm{mg} / \mathrm{kg} \\
\text { daily) }\end{array}$ & $\begin{array}{c}\text { A: sham group }(\mathrm{H} 2 \mathrm{O}) ; \mathrm{B}: \text { OVX } \\
\text { group }(\mathrm{H} 2 \mathrm{O}) ; \mathrm{C}: \mathrm{OVX}+\mathrm{E} 2(22.5 \\
\mathrm{ug} / \mathrm{kg} \text { daily })\end{array}$ & 12 \\
\hline $\begin{array}{l}\text { Song et al. } \\
2016\end{array}$ & $\begin{array}{l}\text { SD rats (body } \\
\text { weight, } \\
240 \pm 12 \mathrm{~g} \text { ) }\end{array}$ & 3 & $\begin{array}{c}18 / 18 / 18 / \\
18\end{array}$ & $\begin{array}{c}\text { A : OVX + naringin }(40 \mathrm{mg} / \mathrm{kg} \\
\text { daily); } \mathrm{B}: \text { OVX + naringin } \\
(100 \mathrm{mg} / \mathrm{kg} \text { daily }) ; \mathrm{C}: \\
\text { OVX + naringin }(300 \mathrm{mg} / \mathrm{kg} \\
\text { daily) }\end{array}$ & B: OVX group (normal saline) & 8 \\
\hline $\begin{array}{l}\text { Wang et al. } \\
2015\end{array}$ & Unclear & 1 & $5 / 5 / 5 / 5$ & $\begin{array}{l}\text { A : OVX naringin }(5 \mathrm{nM}) ; \mathrm{B} \text { : } \\
\text { OVX naringin with } \mathrm{PTH}\end{array}$ & $\begin{array}{c}\text { A: sham vehicle; B : OVX vehicle } \\
\text { (PBS) }\end{array}$ & 6 \\
\hline $\begin{array}{l}\text { Sun et al. } \\
2015\end{array}$ & $\begin{array}{l}\text { SD rats (body } \\
\text { weight, } \\
230 \pm 10 \mathrm{~g})\end{array}$ & 3 & $\begin{array}{l}15 / 15 / 15 / \\
15 / 15\end{array}$ & $\begin{array}{c}\text { A : OVX naringin }(300 \mathrm{mg} / \mathrm{kg} \\
\text { daily); B : OVX naringin plus } \\
\text { treadmill exercise }(300 \mathrm{mg} / \mathrm{kg} \\
\text { daily }+\mathrm{EX})\end{array}$ & $\begin{array}{l}\text { A: sham group }(\mathrm{H} 2 \mathrm{O}) ; \mathrm{B}: \mathrm{OVX} \\
\text { vehicle; } \mathrm{C}: \mathrm{OVX} \text { exercise }\end{array}$ & 12 \\
\hline Li et al. 2013 & $\begin{array}{l}\text { SD rats (body } \\
\text { weight, } 220 \mathrm{~g} \text { ) }\end{array}$ & 3 & $6 / 6 / 6 / 6$ & $\begin{array}{c}\text { A : OVX + naringin }(60 \mathrm{mg} / \mathrm{kg} \\
\text { daily); } \mathrm{B}: \mathrm{OVX}+\text { naringin } \\
(300 \mathrm{mg} / \mathrm{kg} \text { daily); } \mathrm{C}: \\
\text { OVX + naringin }(1500 \mathrm{mg} / \mathrm{kg} \\
\text { daily) }\end{array}$ & A : OVX vehicle (PBS) & 8 \\
\hline Li et al. 2012 & $\begin{array}{l}\text { SD rats (body } \\
\text { weight, } 280 \mathrm{~g} \text { ) }\end{array}$ & 4 & $\begin{array}{c}12 / 12 / 12 / \\
12 / 12\end{array}$ & $\begin{array}{c}\mathrm{A}: \text { OVX }+ \text { naringin }(4 \mathrm{mg} / \mathrm{kg} \\
\text { daily); } \mathrm{B}: \text { OVX }+ \text { naringin }(2 \mathrm{mg} / \\
\mathrm{kg} \text { daily })\end{array}$ & $\begin{array}{l}\text { A: sham group }(\mathrm{H} 2 \mathrm{O}) ; \mathrm{B}: \mathrm{OVX} \\
\text { vehicle }(\mathrm{H} 2 \mathrm{O}) ; \mathrm{C}: \mathrm{OVX}+\mathrm{E} 2\end{array}$ & 13 \\
\hline $\begin{array}{l}\text { Wang et al. } \\
2016\end{array}$ & $\begin{array}{l}\text { SD rats (body } \\
\text { weight, } \\
230 \pm 25 \mathrm{~g})\end{array}$ & 6 & $\begin{array}{c}10 / 10 / 10 / \\
10 / 10\end{array}$ & $\begin{array}{l}\text { A : OVX + naringin }(1 \mathrm{mg} / \mathrm{kg} \\
\text { daily); } \mathrm{B}: \text { OVX + naringin } \\
(10 \mathrm{mg} / \mathrm{kg} \text { daily); C: } \\
\text { OVX + naringin }(100 \mathrm{mg} / \mathrm{kg} \\
\text { daily) }\end{array}$ & A: sham group; $\mathrm{B}: \mathrm{OVX}+\mathrm{N}$ & 4 \\
\hline $\begin{array}{l}\text { Zhao et al. } \\
2016\end{array}$ & $\begin{array}{l}\text { SD rats (body } \\
\text { weight, } \\
230 \pm 20 \mathrm{~g})\end{array}$ & Unclear & $15 / 15$ & A : OVX + naringin $(300 \mathrm{mg} / \mathrm{kg}$ & A : OVX vehicle (normal saline) & 2 \\
\hline
\end{tabular}

TABLE 2: Risk of bias.

\begin{tabular}{|c|c|c|c|c|c|c|c|}
\hline Study & Sample size calculation & $\begin{array}{l}\text { Inclusion } \\
\text { and } \\
\text { exclusion } \\
\text { criteria }\end{array}$ & Randomization & Allocation concealment & $\begin{array}{c}\text { Reporting } \\
\text { of animals } \\
\text { excluded } \\
\text { from } \\
\text { analysis }\end{array}$ & $\begin{array}{c}\text { Blinded } \\
\text { assessment } \\
\text { of outcome }\end{array}$ & $\begin{array}{c}\text { Reporting } \\
\text { potential } \\
\text { conflicts of } \\
\text { interest }\end{array}$ \\
\hline Pang et al 2010 & Unclear & Unclear & Yes & Unclear & Unclear & Yes & No \\
\hline $\begin{array}{l}\text { Shangguan } \\
\text { et al. } 2017\end{array}$ & Unclear & Unclear & Yes & Unclear & Unclear & Yes & No \\
\hline Li et al. 2014 & Unclear & Unclear & Yes & Unclear & Unclear & Yes & No \\
\hline Song et al. 2016 & Unclear & Unclear & Yes & Unclear & Unclear & Yes & No \\
\hline $\begin{array}{l}\text { Wang et al. } \\
2015\end{array}$ & Unclear & Unclear & Yes & Unclear & Unclear & Yes & No \\
\hline Sun et al. 2015 & Unclear & Unclear & Yes & Unclear & Unclear & Yes & No \\
\hline Li et al. 2013 & Unclear & Unclear & Yes & Unclear & Unclear & Yes & No \\
\hline Li et al. 2012 & Unclear & Unclear & Yes & Unclear & Unclear & Yes & No \\
\hline $\begin{array}{l}\text { Wang et al. } \\
2016\end{array}$ & Unclear & Unclear & Yes & Unclear & Unclear & Yes & No \\
\hline Zhao et al. 2016 & Unclear & Unclear & Yes & Unclear & Unclear & Yes & No \\
\hline
\end{tabular}




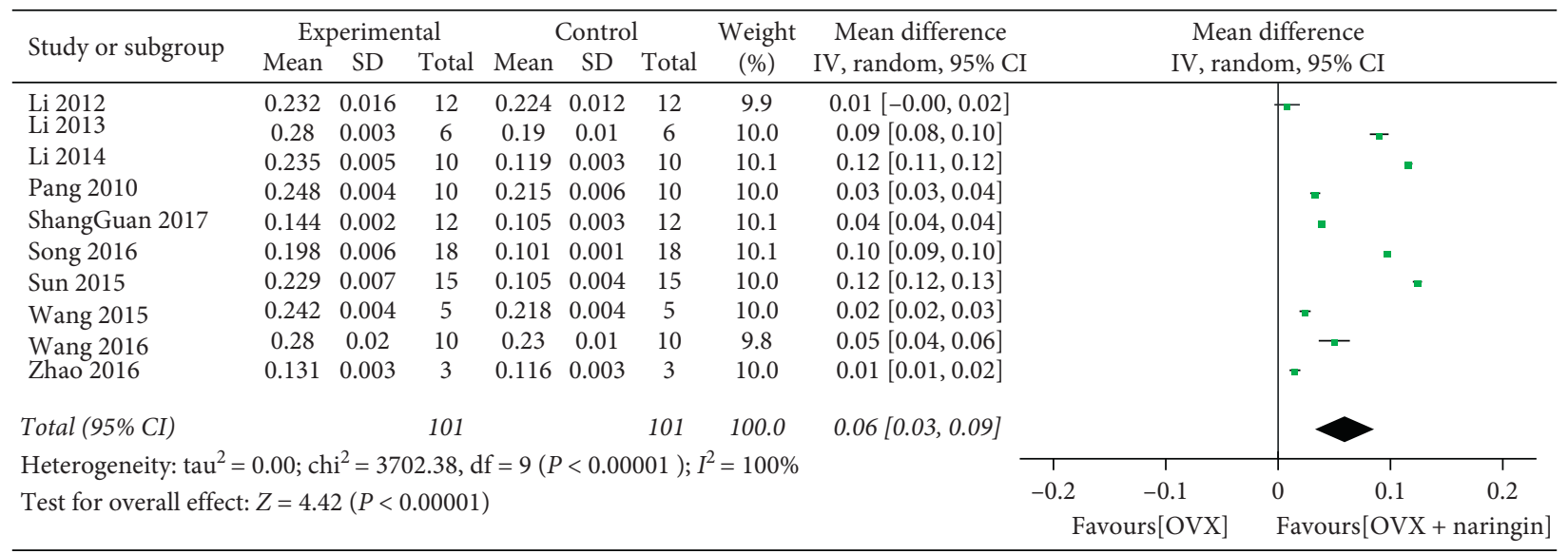

FIGURE 2: BMD changes after naringin treatment.

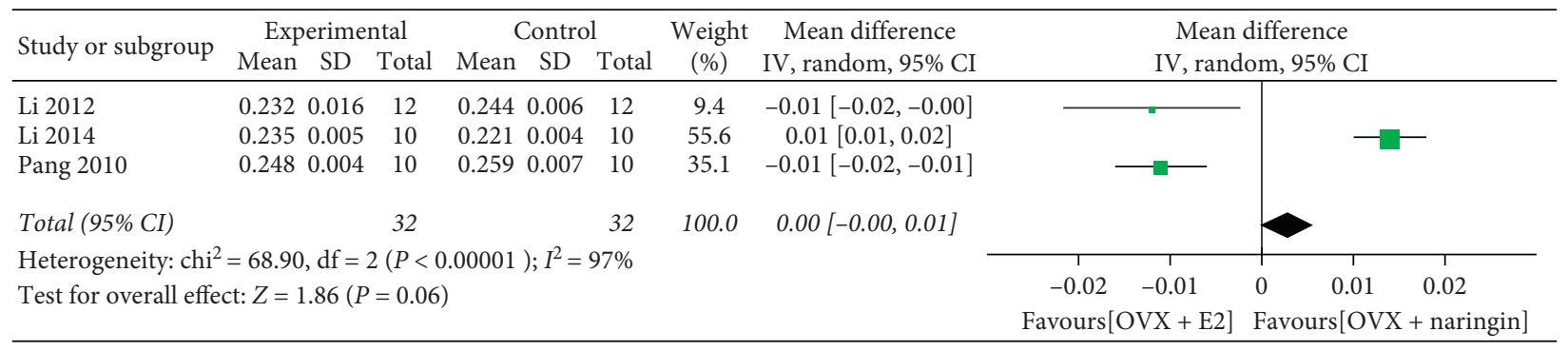

FIGURE 3: Comparison of the effects of naringin and estrogen on BMD.

\begin{tabular}{|c|c|c|c|c|c|c|c|c|c|c|c|}
\hline \multirow{3}{*}{$\frac{\text { Study or subgroup }}{\text { Li } 2013}$} & \multicolumn{3}{|c|}{ Experimental } & \multicolumn{3}{|c|}{ Control } & \multirow{2}{*}{$\begin{array}{c}\text { Weight } \\
(\%)\end{array}$} & \multirow{2}{*}{$\begin{array}{c}\text { Mean difference } \\
\text { IV, random, 95\% CI }\end{array}$} & \multirow{2}{*}{\multicolumn{2}{|c|}{$\begin{array}{c}\text { Mean difference } \\
\text { IV, random, } 95 \% \text { CI }\end{array}$}} & \\
\hline & Mean & SD & Total & Mean & SD & Total & & & & & \\
\hline & 6.7 & 0.5 & 6 & 5.7 & 0.3 & 6 & 28.4 & $1.00[0.53,1.47]$ & & -- & \\
\hline Li 2014 & 6.9 & 0.3 & 10 & 4.1 & 0.5 & 10 & 47.4 & $2.80[2.44,3.16]$ & & & - \\
\hline Sun 2015 & 6.4 & 0.6 & 15 & 4.4 & 0.8 & 15 & 24.2 & $2.00[1.49,2.51]$ & & & -- \\
\hline Total (95\% CI) & & & 31 & & & 31 & 100.0 & $2.09[1.85,2.34]$ & & & \\
\hline \multicolumn{9}{|c|}{ Heterogeneity: $\mathrm{chi}^{2}=35.91, \mathrm{df}=2(P<0.00001) ; I^{2}=94 \%$} & & & \\
\hline \multirow{2}{*}{\multicolumn{9}{|c|}{ Test for overall effect: $Z=16.50(P=0.00001)$}} & -2 & 0 & 2 \\
\hline & & & & & & & & & \multicolumn{3}{|c|}{ Favours[OVX] Favours $[\mathrm{OVX}+$ naringin $]$} \\
\hline
\end{tabular}

Figure 4: BV/TV changes after naringin treatment.

\begin{tabular}{|c|c|c|c|c|c|c|c|c|c|c|c|c|c|}
\hline \multirow{2}{*}{ Study or subgroup } & \multicolumn{3}{|c|}{ Experimental } & \multicolumn{3}{|c|}{ Control } & \multirow{2}{*}{$\begin{array}{c}\text { Weight } \\
(\%)\end{array}$} & \multirow{2}{*}{$\begin{array}{l}\text { Mean difference } \\
\text { IV, fixed, 95\% CI }\end{array}$} & \multirow{2}{*}{\multicolumn{3}{|c|}{$\begin{array}{l}\text { Mean difference } \\
\text { IV, fixed, 95\% CI }\end{array}$}} & \multirow[b]{3}{*}{$=$} & \\
\hline & Mean & SD & Total & Mean & SD & Total & & & & & & & \\
\hline Li 2013 & 23.57 & 0.19 & 6 & 19.13 & 0.16 & 6 & 21.5 & $4.44[4.24,4.64]$ & & & & & \\
\hline Li 2014 & 27.78 & 0.15 & 10 & 20.52 & 0.08 & 10 & 76.6 & $7.26[7.15,7.37]$ & & & & & \\
\hline Sun 2015 & 26.38 & 1.02 & 15 & 19.51 & 0.85 & 15 & 1.9 & $6.87[6.20,7.54]$ & & & & & $\ldots$ \\
\hline \multicolumn{3}{|l|}{ Total (95\% CI) } & 31 & & & 31 & 100.0 & $6.65[6.55,6.74]$ & & & & & 1 \\
\hline \multirow{2}{*}{\multicolumn{9}{|c|}{$\begin{array}{l}\text { Heterogeneity: chi }{ }^{2}=604.11, \mathrm{df}=2(P<0.00001) ; I^{2}=100 \% \\
\text { Test for overall effect: } Z=141.25(P<0.00001)\end{array}$}} & -2 & & 2 & 4 & \\
\hline & & & & & & & & & Favours[OVX & & vours $[\mathrm{OV}$ & $\mathrm{X}+\mathrm{n}$ & ngin] \\
\hline
\end{tabular}

FIGURE 5: Tb.Th changes after naringin treatment.

ERK [38]. Fan et al. revealed that naringin is able to promote BMSC differentiation into osteoblasts, via the upregulation of miR-20a, and the downregulation of PPAR $\gamma$ [39]. Wu et al. demonstrated that naringin increased BMP-2 expression via PI3K, Akt, c-Fos/c-Jun, and AP-1-dependent pathways, which can induce osteoblast proliferation, 
differentiation, and maturation in cultured osteoblasts [40]. In this study, we hypothesized that the mechanism of naringin should be similar to estrogen. Naringin exerted antiosteoporotic effects by binding to estrogen receptors (ERs), which may replace the estrogen replacement therapy (ERT) in clinical use [41], but more experiments were needed to confirm this hypothesis [42].

The STAIR list was used in this systematic review, which was concise and contained the basic criteria that focus on high quality, such as sample size calculation, randomization, allocation concealment, and blinded outcome assessment.

This meta-analysis also had many limitations. First, despite the best efforts we had made, there was no way to ensure that all relevant studies were found. Second, the quality evaluation of this research is low. There was a lack of calculation of sample size, explanation of random allocation method, and reports of animals excluded from analysis. At the same time, there were biases caused by publication bias. In particular, systematic reviews of animal studies were more susceptible to publication bias than clinical studies [43]. Third, all results (BMD, BV/TV, and Tb. Th) were highly heterogeneous in this study, indicating that the results may not be convincing. For BV/TV and Tb.Th index, it was difficult to establish a unified ROI, which resulted in a large heterogeneity between the studies. The different time of OVX and the different dosage and durations of naringin treatment in rats may lead to higher heterogeneity. However, due to the small number of studies, there was limited ability to consider subgroup analyses. Fourth, this study did not accurately infer the optimal concentration of naringin in OVX rats and could not provide guidance for future animal experiments, so more research and analysis are needed.

\section{Conclusions}

In OVX rats model, the BMD, BV/TV, and $\mathrm{Tb}$. Th values of naringin treatment group were significantly increased, which proved that naringin promoted bone formation. At the same time, we speculated that the mechanism of naringin was the same as estrogen, which needs more research to confirm.

$\begin{array}{ll}\text { Abbreviations } \\ \text { OVX: } & \text { Ovariectomized } \\ \text { BMD: } & \text { Mineral density } \\ \text { BV/TV: } & \text { Trabecular bone volume } \\ \text { Tb.Th: } & \text { Trabecular thickness } \\ \text { PRISMA: } & \text { Preferred Reporting Items for Systematic } \\ & \text { Reviews and Meta-Analyses } \\ \text { STAIR: } & \text { Stroke Therapy Academic Industry Roundtable } \\ \text { CI: } & \text { Confidence interval } \\ \text { FDA: } & \text { US Food and Drug Administration } \\ \text { DEXA: } & \text { Dual energy x-ray absorptiometry } \\ \text { ROI: } & \text { Regions of interest } \\ \text { ERs: } & \text { Estrogen receptors } \\ \text { ERT: } & \text { Estrogen replacement therapy } \\ \text { E2: } & \text { 17- } \beta \text {-Estradiol } \\ \text { PTH: } & \text { Parathyroid hormone }\end{array}$

$\begin{array}{ll}\text { EX: } & \text { Exercise } \\ \text { PBS: } & \text { Phosphate-buffered saline } \\ \text { N: } & \text { Nothing. }\end{array}$

\section{Data Availability}

The data used to support the findings of this study are available from the corresponding author upon request.

\section{Conflicts of Interest}

The authors declare that they have no conflicts of interest.

\section{Authors' Contributions}

ZZ designed the study and prepared the first draft of the paper. ZZ, WJX, and YYL contributed to the experimental work. $\mathrm{ZOZ}$ and $\mathrm{WZ}$ were responsible for statistical analysis of the data. WZ is guarantor. All authors revised the paper critically for intellectual content and approved the final version. All authors agree to be accountable for the work and to ensure that any questions relating to the accuracy and integrity of the paper are investigated and properly resolved.

\section{Acknowledgments}

This research was supported by Natural Science Foundation of Jiangsu Province (CN) (SBK2017043261). Funding was provided in the design of the study and collection, analysis, and interpretation of data and in writing the manuscript.

\section{References}

[1] C.-H. Chen, S.-J. Lim, J.-K. Oh et al., "Teriparatide in East Asian postmenopausal women with osteoporosis in a realworld setting: a baseline analysis of the Asia and Latin America fracture observational study (ALAFOS)," Clinical Interventions in Aging, vol. 15, pp. 111-121, 2020.

[2] S. Shetty, B. John, S. Mohan, and T. V. Paul, "Vertebral fracture assessment by dual-energy X-ray absorptiometry along with bone mineral density in the evaluation of postmenopausal osteoporosis," Archives of Osteoporosis, vol. 15, no. 1 , p. $25,2020$.

[3] R. Recker, D. Dempster, B. Langdahl et al., "Effects of odanacatib on bone structure and quality in postmenopausal women with osteoporosis: 5-year data from the phase 3 longterm odanacatib fracture trial (LOFT) and its Extension," Journal of Bone and Mineral Research, vol. 35, no. 7, p. 1289, 2020.

[4] J. Li, X. Chen, L. Lu, and X. Yu, "The relationship between bone marrow adipose tissue and bone metabolism in postmenopausal osteoporosis," Cytokine \& Growth Factor Reviews, vol. 52, pp. 88-98, 2020.

[5] J. I. Francisco, Y. Yu, R. A. Oliver, and W. R. Walsh, "Relationship between age, skeletal site, and time post-ovariectomy on bone mineral and trabecular microarchitecture in rats," Journal of Orthopaedic Research, vol. 29, no. 2, pp. 189-196, 2011.

[6] S. Bharti, N. Rani, B. Krishnamurthy, and D. Arya, "Preclinical evidence for the pharmacological actions of naringin: a review," Planta Medica, vol. 80, no. 6, pp. 437-451, 2014. 
[7] H. Awasthi, D. Mani, D. Singh, and A. Gupta, "The underlying pathophysiology and therapeutic approaches for osteoporosis," Medicinal Research Reviews, vol. 38, no. 6, pp. 2024-2057, 2018.

[8] F. Li, X. Sun, J. Ma et al., "Naringin prevents ovariectomyinduced osteoporosis and promotes osteoclasts apoptosis through the mitochondria-mediated apoptosis pathway," Biochemical and Biophysical Research Communications, vol. 452, no. 3, pp. 629-635, 2014.

[9] W. Ggengqi, W. Liming, X. Lin, S. Daoxi, T. Tian, and $\mathrm{X}$. Wenqiang, "Effect of naringin on osteoporotic fracture healing in ovariectomized rats," Acta Universitatis Traditionis Medical Issinensis Pharmacologiaeque Shanghai, vol. 30, no. 4, pp. 73-79, 2016.

[10] Z. Zhao, X. Ma, J. Ma, X. Sun, F. Li, and J. Lv, "Naringin enhances endothelial progenitor cell (EPC) proliferation and tube formation capacity through the CXCL12/CXCR4/PI3K/ Akt signaling pathway," Chemico-biological Interactions, vol. 286, pp. 45-51, 2018.

[11] J.-y. Long, J.-m. Chen, Y.-j. Liao, Y.-j. Zhou, B.-y. Liang, and Y. Zhou, "Naringin provides neuroprotection in CCL2-induced cognition impairment by attenuating neuronal apoptosis in the hippocampus," Behavioral and Brain Functions, vol. 16 , no. 1 , p. $4,2020$.

[12] H. Zhao, M. Liu, H. Liu, R. Suo, and C. Lu, "Naringin protects endothelial cells from apoptosis and inflammation by regulating the Hippo-YAP Pathway," Bioscience Reports, vol. 40, no. 3, 2020.

[13] R. Chen, Q.-L. Qi, M.-T. Wang, and Q.-Y. Li, “Therapeutic potential of naringin: an overview," Pharmaceutical Biology, vol. 54, no. 12, pp. 3203-3210, 2016.

[14] K. Shirani, B. S. Yousefsani, M. Shirani, and G. Karimi, "Protective effects of naringin against drugs and chemical toxins induced hepatotoxicity: a review," Phytotherapy Research, vol. 34, no. 8, p. 1734, 2020.

[15] W. M. Bernardo, "PRISMA statement and PROSPERO," International Braz J Urol, vol. 43, no. 3, pp. 383-384, 2017.

[16] A. Thomas, J. Detilleux, P. Flecknell, and C. Sandersen, "Impact of stroke therapy academic industry roundtable (STAIR) guidelines on peri-Anesthesia care for rat models of stroke: a meta-analysis comparing the years 2005 and 2015," PloS One, vol. 12, no. 1, p. e0170243, 2017.

[17] J. P. T. Higgins, S. G. Thompson, J. J. Deeks, and D. G. Altman, "Measuring inconsistency in meta-analyses," BMJ, vol. 327, no. 7414, pp. 557-560, 2003.

[18] W.-Y. Pang, X.-L. Wang, S.-K. Mok et al., "Naringin improves bone properties in ovariectomized mice and exerts oestrogen-like activities in rat osteoblast-like (UMR-106) cells," British Journal of Pharmacology, vol. 159, no. 8, pp. 1693-1703, 2010.

[19] W. J. Shangguan, Y. H. Zhang, Z. C. Li, L. M. Tang, J. Shao, and H. Li, "Naringin inhibits vascular endothelial cell apoptosis via endoplasmic reticulum stress- and mitochondrial-mediated pathways and promotes intraosseous angiogenesis in ovariectomized rats," International Journal of Molecular Medicine, vol. 40, no. 6, pp. 1741-1749, 2017.

[20] N. Song, Z. Zhao, X. Ma et al., "Naringin promotes fracture healing through stimulation of angiogenesis by regulating the VEGF/VEGFR-2 signaling pathway in osteoporotic rats," Chemico-biological Interactions, vol. 261, pp. 11-17, 2017.

[21] D. Wang, W. Ma, F. Wang et al., "Stimulation of wnt/ $\beta$-catenin signaling to improve bone development by naringin via interacting with AMPK and Akt," Cellular Physiology and Biochemistry, vol. 36, no. 4, pp. 1563-1576, 2015.
[22] X. Sun, L. Fengbo, M. Xinlong et al., "The effects of combined treatment with naringin and treadmill Exercise on osteoporosis in ovariectomized rats," Scientific Reports, vol. 5, no. 1, p. 13009, 2015.

[23] N. Li, Y. Jiang, P. H. Wooley, Z. Xu, and S. Y. Yang, "Naringin promotes osteoblast differentiation and effectively reverses ovariectomy-associated osteoporosis," Journal of Orthopaedic Science: Official Journal of the Japanese Orthopaedic Association, vol. 18, no. 3, pp. 478-485, 2013.

[24] L. Jinping, L. Xin, M. Xinmin, L. Shijie, and G. Guoxin, "Effects of naringin on bone biomechanics and bone mineral density in postmenopausal osteoporosis rats," Journal of Modern Medicine and Health, vol. 28, no. 5, pp. 683-684.

[25] Z. Zhihu, M. Xinming, S Xiaolei et al., "Effect and mechanism of naringin on vascular development of fracture callus in ovariectomized rats," Chinese Journal of Orthopaedics, vol. 36, no. 3, pp. 177-183, 2016.

[26] M. Y. George, E. T. Menze, A. Esmat, M. G. Tadros, and E. ElDemerdash, "Potential therapeutic antipsychotic effects of Naringin against ketamine-induced deficits in rats: involvement of Akt/GSK-3 $\beta$ and Wnt/ $\beta$-catenin signaling pathways," Life Sciences, vol. 249, p. 117535, 2020.

[27] N. Mathavan, M. J. Turunen, M. Tägil, and H. Isaksson, "Characterising bone material composition and structure in the ovariectomized (OVX) rat model of osteoporosis," Calcified Tissue International, vol. 97, no. 2, pp. 134-144, 2015.

[28] D. N. Kalu, "The ovariectomized rat model of postmenopausal bone loss,” Bone and Mineral, vol. 15, no. 3, pp. 175-191, 1991.

[29] I. Meyer, S. L. Morgan, A. D. Markland, J. M. Szychowski, and H. E. Richter, "Pelvic floor disorder symptoms and bone strength in postmenopausal women," International Urogynecology Journal, vol. 31, no. 9, p. 1777, 2020.

[30] B. D. Johnston and W. E. Ward, "The ovariectomized rat as a model for studying alveolar bone loss in postmenopausal women," BioMed Research International, vol. 2015, Article ID 635023, 1 page, 2015.

[31] T. Ikeda, H. Kaji, Y. Tamura, and M. Akagi, "Once-weekly teriparatide reduces serum sclerostin levels in postmenopausal women with osteoprosis," Journal of Orthopaedic Science, vol. 24, no. 3, pp. 532-538, 2019.

[32] M. Fotouk-Kiai, S. R. Hoseini, N. Meftah et al., "Relationship between Helicobacter pylori infection (HP) and bone mineral density (BMD) in elderly people," Caspian Journal of Internal Medicine, vol. 6, no. 2, pp. 62-66, 2015.

[33] T. J. Ziemlewicz, A. Maciejewski, N. Binkley, A. D. Brett, J. K. Brown, and P. J. Pickhardt, "Opportunistic quantitative CT bone mineral density measurement at the proximal femur using routine contrast-Enhanced scans: direct comparison with DXA in 355 Adults," Journal of Bone and Mineral Research, vol. 31, no. 10, pp. 1835-1840, 2016.

[34] Y. Jin, T. Zhang, J. P. Y. Cheung et al., "A novel mechanical parameter to quantify the microarchitecture effect on apparent modulus of trabecular bone: a computational analysis of ineffective bone mass," Bone, vol. 135, p. 115314, 2020.

[35] R. Inai, R. Nakahara, Y. Morimitsu et al., "Bone microarchitectural analysis using ultra-high-resolution CT in tiger vertebra and human tibia," European Radiology Experimental, vol. 4, no. 1, p. 4, 2020.

[36] N. M. Jandl, T. Rolvien, T. Schmidt et al., "Impaired bone microarchitecture in patients with hereditary hemochromatosis and skeletal complications," Calcified Tissue International, vol. 106, no. 5, p. 465, 2020.

[37] X. Y. Qiao, Y. Xiao, B. W Xia et al., "High-resolution peripheral quantitative computed tomography for the 
assessment of bone strength and structure in obstructive sleep Apnea patients," Zhongguo Yi Xue Ke Xue Yuan Xue Bao Acta Academiae Medicinae Sinicae, vol. 41, no. 6, pp. 761-771, 2019.

[38] E. S. M. Ang, X. Yang, H. Chen, Q. Liu, M. H. Zheng, and J. $\mathrm{Xu}$, "Naringin abrogates osteoclastogenesis and bone resorption via the inhibition of RANKL-induced NF- $\kappa \mathrm{B}$ and ERK activation," FEBS Letters, vol. 585, no. 17, pp. 2755-2762, 2011.

[39] J. Fan, J. Li, and Q. Fan, "Naringin promotes differentiation of bone marrow stem cells into osteoblasts by upregulating the expression levels of microRNA-20a and downregulating the expression levels of PPAR $\gamma$," Molecular Medicine Reports, vol. 12, no. 3, pp. 4759-4765, 2015.

[40] J.-B. Wu, Y.-C. Fong, H.-Y. Tsai, Y.-F. Chen, M. Tsuzuki, and C.-H. Tang, "Naringin-induced bone morphogenetic protein2 expression via PI3K, Akt, c-Fos/c-Jun and AP-1 pathway in osteoblasts," European Journal of Pharmacology, vol. 588, no. 2-3, pp. 333-341, 2008.

[41] K. Wiren, A. Chapman Evans, and X. Zhang, "Osteoblast differentiation influences androgen and estrogen receptoralpha and -beta expression," Journal of Endocrinology, vol. 175, no. 3, pp. 683-694, 2002.

[42] R. O. C. Oreffo, V. Kusec, A. S. Virdi et al., "Expression of estrogen receptor-alpha in cells of the osteoclastic lineage," Histochemistry and Cell Biology, vol. 111, no. 2, pp. 125-133, 1999.

[43] N. V. Puranik, P. Srivastava, G. Bhatt, D. J. S. John Mary, A. M. Limaye, and J. Sivaraman, "Determination and analysis of agonist and antagonist potential of naturally occurring flavonoids for estrogen receptor $(\mathrm{ER} \alpha)$ by various parameters and molecular modelling approach," Scientific Reports, vol. 9, no. 1, p. 7450, 2019. 